Est Ag 46 (2011) 5-32

\title{
Las crisis sacerdotales de San Agustín
}

\author{
Pío DE LuIs Vizcaíno, OSA*
}

RESUMEN: Las crisis sacerdotales no son algo nuevo en la Iglesia. San Agustín mismo las sufrió. Sus escritos nos dejan constancia de tres: una al inicio de su ministerio (cf. Conf. 10,43,70), otra hacia la mitad del mismo (cf. En. in. Ps. 54,8) y otra en los años finales (cf. Ep. 209,10). En el artículo se estudian las características de cada una y el modo cómo el santo las superó.

PALABRAS CLAVE: Crisis, sacerdocio, siervo de Dios, Escritura, Jesucristo, Pablo, ejemplo.

ABSTRACT: Crises in priesthood are no novelty to the Church. Saint Augustine himself experienced them. Accounts of three such instances are found in his writings: one at the beginning of his ministry (Conf. 10,43,70), one at about half way through it (En. in. Ps. 54,8), and another towards its end (Ep. 209,10). This article examines the characteristics of each crisis and how the Saint overcome them.

KEY WORDS: Crises, Priesthood, Servant of God, Scripture, Jesus Christ, Paul, example.

Hablar de crisis está a la orden del día en múltiples ámbitos: el político, el económico, el social y también el eclesial. En este último, una de las crisis más palpables tiene como sujetos a los sacerdotes. De esta crisis me propongo hablar.

Entiendo aquí por crisis una situación de dificultad que lleva al sacerdote a cuestionarse su ejercicio del ministerio cuando no el ministe-

\footnotetext{
* Profesor de Patrología del Estudio Teológico Agustiniano de Valladolid. pioluvi@hotmail.com
} 
rio en sí y que puede llevarle a contemplar el abandono del mismo o a abandonarlo de hecho como única forma de superar esa dificultad.

Pero mi propósito no es hablar de las crisis sacerdotales en abstracto, sino de las vividas por san Agustín. Lo que caracteriza la crisis sacerdotal actual quizá sea su virulencia, no su existencia, bien conocida en el pasado eclesial. Es fácil comprender que las altas exigencias del ministerio sacerdotal hayan hecho tambalearse, aunque por distintos motivos, tanto a espíritus sólidos como a espíritus vanos. Espíritu sólido fue, sin duda alguna, san Agustín, pero eso no le libró del embate de la crisis; hasta se puede decir que, en su caso, fue esa misma solidez la causa desencadenante. Tres son las crisis personales de las que el santo nos dejó constancia en sus escritos. A la primera alude en estos términos: "Aterrado por mis pecados y por el peso de mi miseria, en mi interior había rumiado y proyectado una fuga a la soledad" (Conf. 10,43,70); a la segunda, en estos: "...muchas veces surge en el alma del siervo de Dios el deseo de la soledad sólo por causa de la infinidad de tribulaciones y de escándalos, y dice: ¿Quién me diera alas!" (para huir al desierto) (Coment. Sal. $54,8)$; a la tercera en estos otros: "He de confesar a tu Beatitud que... pienso retirarme del ejercicio del ministerio episcopal y entregarme a los lamentos dignos de mi error..." (Carta 209,10). Las tres crisis serán objeto de nuestra consideración. Primero indicaremos su naturaleza y luego su superación por el santo.

\section{Las crisis}

\section{a) Primera crisis (Conf. 10,43,70)}

San Agustín presenta su primera crisis como el proyecto madurado en su interior de abandonar el ejercicio del ministerio sacerdotal. De lo que propiamente informa el texto es de un proyecto de huir a la soledad. Pero el pasaje sólo alcanza pleno sentido si se sobrentiende que esa huida comportaba la renuncia al ejercicio de dicho ministerio.

A esta primera crisis no es posible asignarle fecha exacta, pero sí fijarle un terminus ante quem. Obviamente fue anterior a la conclusión del libro décimo de las Confesiones, obra en la que el santo nos informa de ella y que, según opinión común, fue compuesta entre el año 397 y el 401 ó 403. Los autores no han llegado a un acuerdo sobre la coyuntura precisa en la que el santo proyectó esa huida a la soledad. Mientras unos piensan en el momento de la conversión, otros se inclinan por el de la 
ordenación presbiteral o por el de la consagración episcopal ${ }^{1}$. Si se tratase del momento de la conversión, no cabría hablar de crisis sacerdotal. Pero esta interpretación no es aceptable porque, de hecho, el santo se retiró a la soledad de Casiciaco, sin sentir que Dios se lo prohibiera. Podía pensarse en el momento de la ordenación presbiteral, como respuesta a posteriori a la violencia de que había sido objeto ${ }^{2}$. Pero san Agustín no nos parece un espíritu voluble, capaz de tomar decisiones contrarias en tan poco tiempo. La decisión de huir a la soledad nos parece que encaja mejor en el contexto de su ordenación episcopal. Dos hechos favorecen esta interpretación. Uno, que el obispo Valerio tuvo escondido durante algún tiempo a su presbítero por temor a que otras Iglesias sin pastor se lo secuestrasen para ordenarlo de obispo; otro, las acusaciones vertidas contra él por los donatistas y hasta por Megalio de Calama, el obispo primado de la provincia de Numidia, que tenía que ordenarlo ${ }^{4}$. Aunque éste se vio obligado luego a retirar en público sus acusaciones por falta de pruebas y acabó ordenándolo, es comprensible que el presbítero de Hipona se sintiese más que molesto y que durante el período en que tuvo que vivir oculto proyectase huir a la soledad. En esa dirección confluye también lo que escribe el santo pocas líneas después de referir su proyecto de huida: "No me calumnien los soberbios, pues

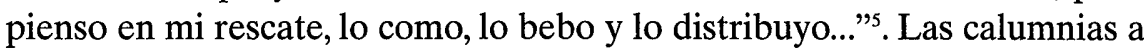
que alude bien pueden haber sido las sufridas en el contexto de su ordenación episcopal.

${ }^{1}$ Cf. G. MADEC, Augustin prêtre. Quelques notes pour la célébration d'un $16^{e}$ centenaire, 391-1991, en Lectures Augustiniennes, Paris 2001, 59-74: 64. Publicado previamente en De Tertullien aux Mozarabes I, Antiquité tardive et christianisme ancien (IIIe-VIe siècles). Mélanges offerts à Jacques Fontaine, Paris 1992, 185-199.

${ }^{2}$ Es la opinión de J. J. Donnell: "But that thought of flight creeps in. What if Augustine were writing to his bishop from Tagaste? What if, on the morning after his ordination, he had really fled Hippo, gone back home, and shuddered at the thought of what happened? Id he then decided that he had no choice but to accept what hat been laid on him, messages like the letter he sent to Valerius would be just the reassurance, to say nothing of the cover, that the situation required. It gave him time to settle his affairs in Tagaste and prepare for his move. As a devout landowner, he had not thought highly of clergy (most of whom came from well below him on the social ladder) (Augustine. A new Biography, New York 2005, p. 25).

${ }^{3}$ Cf. Possidius, Vita Augustini 8,1-3.

${ }^{4}$ Cf. C. litt. Pet. 3,16,19; C. Cresc. 3,80,92. Cf. P. LANGA, Acusaciones contra san Agustín en la Conferencia de Cartago, en Obras Completas de san Agustín XXXII, BAC 498, nota complementaria 68, pp. 936-937; y Valerio de Hipona, en Augustinus 38 (1993) 303-327: 321

${ }^{5}$ Conf. $10,43,70$. 
Como hemos indicado, la crisis se resolvía en huir a la soledad. ¿A qué soledad se refiere? Lo primero que puede venir a la mente del lector es pensar en parajes solitarios, en lugares descampados, en la vida eremítica que la tradición monástica conocía perfectamente. Pero esta interpretación es difícil de aceptar en el caso de Agustín, ante todo por razones personales. En una obra temprana, Las Costumbres de la Iglesia Católica, el santo, a la vez que proclama su admiración por los eremitas, reconoce que ese estilo de vida supera su personal capacidad ${ }^{6}$. Su carácter no era el del solitario, pues necesitaba de los amigos para vivir ${ }^{7}$. Huir a la soledad significaba entonces para él abandonar el ajetreo de la vida pública y retirarse a la paz del monasterio ${ }^{8}$.

La causa de la crisis la expone san Agustín mismo: la conciencia de sus pecados y el peso de su miseria. Las críticas antes mencionadas contra él podían haber sido la ocasión, pero no propiamente la causa. Según sus palabras, la crisis tenía una base moral. ¿De qué pecados y miseria se trata? Podría pensarse en su pasado maniqueo y un tanto libertino que le reprochaban los donatistas, considerado como un obstáculo para su ministerio pastoral ${ }^{9}$. En contra de esta interpretación estaría el territus, el sentirse aterrado, pues si algo tenía claro Agustín es que sus pecados le habían sido perdonados en el bautismo ${ }^{10}$. Aunque una cosa sería la cuestión moral en sí misma y otra el efecto negativo que podía tener para su ministerio. Pero quizá lo más acertado sea no salirnos del libro décimo de las Confesiones. Inmediatamente antes de referir el proyecto de fuga, el santo obispo manifiesta su esperanza de que Dios sanará todas sus dolencias por medio de Cristo, "porque muchas y grandes son mis dolencias, sí; muchas y grandes son, aunque mayor es tu Medicina"11. ¿A qué dolencias se refiere? Basta pensar que el santo ha hecho previamente un riguroso y penetrante examen de conciencia que le ha permitido detectar también aspectos poco luminosos en relación con su condición de pastor de la Iglesia: el afán de ser temido y amado de los hombres buscando en ello un gozo que no es gozo, el que le agradaba ser amado y temido no por

${ }^{6}$ Mor. eccl. 1, 31,67.

${ }^{7} \mathrm{Cf}$. T. VIÑAS, La amistad en la vida religiosa: interpretación agustiniana de la vida en comunidad, Madrid 1995, pp. 54-83; M. A. MCNAMARA, Friends and Friendship for Saint Augustine. Preface by John O'Meara Alba House, 1964 (traducción italiana: L'amicizia in S. Agostino, Milano 2000, p. 200).

${ }^{8}$ Así se desprende, por ejemplo, de en. Ps. 54,9.

${ }^{9}$ Cf. En. Ps. 36,3,19-20.

${ }^{10}$ Cf. Conf. 2,7,15; 9,6,14.

${ }^{11}$ Cf. Conf. 10,42,69. 
Dios sino en su lugar ${ }^{12}$, la complacencia en las alabanzas, el que la aprobación ajena aumentaba el gozo de cualquier bien suyo, el que la vituperación lo disminuía, etc. ${ }^{13}$. A las alabanzas que puede recibir el pastor como peligro moral alude el santo en repetidas ocasiones ${ }^{14}$.

\section{b) Segunda crisis (Coment. al salmo 54,8)}

La segunda crisis se manifiesta también como deseo de retirarse al desierto, anhelando tener alas para poder hacerlo. En esta ocasión el santo no habla explícitamente de sí mismo, sino en forma genérica de un siervo de Dios; pero no cabe sino entender que está refiriendo experiencias personales.

Los autores tampoco han llegado a un acuerdo sobre la fecha en que fue predicado el Comentario al salmo 54, texto en que el santo habla de la crisis. Aunque alguno ha pensado en una fecha temprana ${ }^{15}$, los estudiosos más recientes abogan por una más tardía, el año $408^{16}$, o sea, unos 17 años después de la ordenación sacerdotal y unos 12 después de la episcopal. La experiencia presupone ya un largo periodo de ejercicio del ministerio pastoral que le ha dado tiempo a probar sabores y sinsabores. $\mathrm{El}$ predicador no parece aludir a una circunstancia concreta, sino a una vivencia repetida (plerumque), ni piensa en un abandono definitivo del ministerio, sino sólo en un retiro temporal (separarer paululum). De todos modos, las circunstancias que suscitan ese deseo permiten encuadrarlo en la categoría de crisis.

En la Biblia de Jerusalén el salmo 54 lleva por título: "Oración de un calumniado". Tras pedir a Dios que le escuche, el salmista describe su situación lastimosa. Estas son sus palabras según la versión que utiliza san Agustín": "Me hallo triste en mi prueba, y estoy turbado por la voz del enemigo y por la tribulación que me causa el pecador, porque han arroja-

${ }^{12}$ Cf. Conf. $10,36,59$.

${ }^{13}$ Cf. Conf. 10,37,61-62.

${ }^{14}$ Cf. Ep. 22,2,8-9; S. 339,1; Io eu. tr. 57, 6 .

${ }^{15}$ S. ZARB, Chronologia Enarrationum S. Augustini in Psalmos, en Angelicum 14 (1937) 516-527.

${ }^{16} \mathrm{Cf}$. H. RondeT, Chronologie augustinienne: Le sermon sur le Psaume 54, en Historisches Jahrbuch 77 (1957) 403-407: 403; A.-M. LA BONNARDIÈRE, Psaume 13,3 et l'interpolation de Rom. 3,13-18 dans l'oeuvre de saint Agustín, en Recherches Augustiniennes 4 (1966) 49-6557.

${ }^{17}$ Estas, en cambio, en la de la Biblia de Jerusalén: "Gimo ante la voz del enemigo bajo el abucheo del impío, pues vierten sobre mí falsedades y con saña me hostigan. Se me 
do sobre mí la iniquidad y en su ira me entenebrecían. En mi interior se ha turbado mi corazón y me sobrevino el miedo a la muerte. La situación descrita le arranca esta exclamación: "iQuién me dará alas como a la paloma, y volaré y reposaré!". Luego añade qué hizo: "He aquí que me alejé huyendo y me establecí en el desierto". Por último señala qué esperaba: "Esperaba a quien me salvase del miedo y de la tempestad" (Sal 54,4-9).

La situación sufrida por el salmista la considera el predicador como anuncio de la que vive cierto cristiano, descrita en estos términos: "Los ultrajes de estos (enemigos), que aumentan sin cesar y me cubren de sombra, irritan mis ojos, alteran mi luz, hieren mi corazón, dan muerte a mi alma". También reformula su deseo: "Quisiera alejarme pues soy débil, no sea que quedándome acumule pecados sobre pecados, $\mathrm{o}$, a lo menos, quisiera alejarme un poco de los hombres para que mi herida no reciba más golpes, para volver sano a mi campo de ejercitación". Acto seguido, ese cristiano pasa a ser un ministro de la Iglesia con el que se identifica el pastor Agustín: "Son cosas que suceden, hermanos, y por eso con frecuencia surge en el alma del siervo de Dios el deseo de la soledad, por la única razón de las muchas tribulaciones y motivos de tropiezo que sufre, y dice: ¿Quién me dará alas?’. La pregunta revela la presencia de la crisis.

El predicador deja de lado provisionalmente la continuación del salmo y se detiene en las tribulaciones aludidas, causantes del deseo de abandonar, aunque sólo sea temporalmente, el ministerio. Pero antes vuelve la mirada al apóstol san Pablo que, no obstante toda su grandeza, también se sintió turbado en su actividad, aduciendo como prueba sus palabras: Por lo demás, que nadie me moleste (Gal 6,17). Palabras que, en la interpretación agustiniana, coinciden en su significado con estas otras del salmo 118: El hastío se apoderó de mí a causa de los pecadores que abandonan tu ley (Sal 118,53). El recurso a estos textos revelados manifiesta que detrás de la crisis había un problema de relación con determinada clase de personas: los pecadores, siempre molestos. Tras aducir la doble referencia bíblica, pasa a referir las tribulaciones. "Muchas veces -dice- el ministro intenta corregir a determinadas personas, aviesas y torcidas que están confiadas a su cura pastoral; pero ante ellas fracasa toda su habilidad y vigilancia y, al no lograr que se corrijan, sufre inevitable-

estremece dentro el corazón, me asaltan pavores de muerte; miedo y temblor me invaden, un escalofrío me atenaza". Luego el salmista expone su deseo: “QQuién me diera alas como a la paloma, para volar y reposar!”, y añade qué haría: “Huiría entonces lejos, en el desierto moraría". Concluye indicando lo que espera: "iEn seguida encontraría un asilo contra el viento enfurecido y la tormenta" (Sal 54,4-9). 
mente. Tanto más que esos que rehúsan corregirse están unidos a él por su condición humana y, a veces, por su condición de miembros de la Iglesia”. Entonces todo son interrogantes: “¿Qué hacer? ¿A dónde ir? ¿A dónde retirarse para no tener que padecer todo eso?". No sin antes haberse asegurado que su conciencia está tranquila: "Hice cuanto pude y estuvo a mi alcance, y veo que de nada me sirvió; todos mis esfuerzos resultaron baldíos, sólo me queda sufrir"18.

En esa situación, buscando aquietar su corazón, se pregunta ¿Quién me dará alas? No cualesquiera alas sino las de la paloma, que -dice el predicador- "cuando la molestan, emprende el vuelo, pero no pierde el amor". Sigue el santo: "Entonces ¿qué dice este amante -así describe al siervo de Dios, es decir, al ministro-?". "No puedo soportar los ultrajes de los hombres: rechinan sus dientes, se dejan llevar del furor, montan en cólera, con su ira me amilanan, no puedo serles útil". "No puedo soportar los ultrajes de los hombres": he aquí un problema de relación con algunos de sus fieles. El suyo es un amor no correspondido: él, amante que da amor, no recibe amor; su recompensa es el insulto, la cólera y la ira contra él. Tal es la causa de la crisis que suscita su deseo de huir a la soledad, manifestado a continuación: “¡Ojalá pudiera descansar en algún sitio separado de ellos físicamente, pero no en el afecto, para evitar que se altere en mí el amor! No puedo serles de provecho con mis palabras y diálogo; tal vez lo sea orando por ellos" ${ }^{\prime 19}$. El amante que no es recompensado con amor quiere no perder el amor: desea separarse físicamente de ellos, pero manteniendo el amor, aun no correspondido.

\section{c) Tercera crisis (Cartas 209 y 20*)}

Esta tercera crisis es más clara, más puntual y más concreta. El obispo de Hipona escribe con todas las letras al papa Celestino $\mathrm{I}^{20}$ que piensa retirarse del ejercicio del ministerio episcopal ${ }^{21}$.

La carta que nos informa de esta decisión fue escrita en el año 422. El texto nos permite saber que la crisis la suscitó un error personal. Una decisión de ese calibre presupone un error de bulto o, al menos, sentido como particularmente grave y cargado de consecuencias. Afortunadamente sabe-

\footnotetext{
${ }^{18}$ Cf. En. Ps. 54,8 .

${ }^{19}$ En. Ps. 54,8.

${ }^{20}$ Nombrado obispo en el año 422, gobernó la iglesia romana hasta el 432.

${ }^{21}$ Cf. Ep. 209,10.
} 
mos cuál fue, incluso con precisión de detalles aportados por el mismo san Agustín en dos cartas, la 209 y la 20* entre las de Divjak. No pudiendo entrar en todos los pormenores, nos limitamos a los datos esenciales ${ }^{22}$.

El error consistió en haber nombrado como obispo de una pequeña población a algo más de $50 \mathrm{kms}$. de Hipona, Fussala, a un joven totalmente inepto y, sobre todo, indigno, de nombre Antonino ${ }^{23}$. Para entender la gravedad que atribuye san Agustín a su error es preciso colocar el hecho en su contexto socio-eclesial. Los habitantes de dicha población acababan de pasar del cisma donatista a la Iglesia católica, como consecuencia de la nueva situación surgida tras la Conferencia de Cartago del 411 cuyo resultado fue la supresión legal del cisma donatista; esa circunstancia la hacía merecedora de un cuidado pastoral especial. Como el santo no podía prestárselo desde Hipona, consideró que lo más oportuno era proveerla de un obispo propio que siguiese sus pasos de cerca. Con esa finalidad eligió al candidato que consideraba adecuado y solicitó la presencia del primado de la provincia eclesiástica, un anciano ${ }^{24}$, para que procediera a la ordenación. Pero, llegado el momento, el elegido rehusó de forma tajante ser ordenado ${ }^{25}$. En situación tan comprometida, el santo presentó para el ministerio al mencionado Antonino, criado en el monasterio de clérigos y en posesión del oficio de lector en la Iglesia de Hipona, de poco más de 20 años ${ }^{26}$, pero que tenía a su favor el hecho de conocer la lengua púnica ${ }^{27}$, hablada en aquel lugar. Era tal el prestigio de san Agus-

${ }^{22}$ Sobre todo este asunto, cf. W. FREND, Fussala: Augustine's crisis of credibility (Ep. $\left.20^{*}\right)$, en Les lettres de saint Augustin découvertes par Johannes Divjak. Communications présentées au colloque des 20 et 21 septembre 1982, Paris 1983 (= Études Augustiniennes), 251-265; S. LANCEL, L'affaire d'Antoninus de Fussala: pays, choses et gens de la Numidie d'Hippone saisis dans la durée d'une procédure d'enquête episcopale (Ep. 20*), en ibid. pp. 267-285, y CH. MunIER, La question des appels à Rome d'après la Lettre 20* d'Augustin, en ibid. pp. 287-299.

${ }^{23}$ Cf. S. LANCEL, L'affaire d'Antoninus, pp. 281-283.

${ }^{24}$ Probablemente, Silvano de Summa. Sobre él, cf. A. MANDouze, Prosopographie chrétienne du Bas-Empire 1. D'après la documentation élaborée par A.-M. La Bonnardière, avec la collaboration de C.-H. Lacroix e.a., Paris 1982, 1081-1083. La primacía no dependía de una sede episcopal ni de una elección, sino que recaía siempre sobre el obispo que llevaba más años ordenado.

${ }^{25}$ Cf. Ep. 209,3; 20*,3.

${ }^{26}$ Cf. Ep. $20^{*}, 1-3$. Téngase en cuenta que el joven había sido propuesto para presbítero previamente, en ausencia de Agustín, y que había renunciado (Ep. 20*,2).

${ }^{27}$ Cf. Ep. 20*,3. A este respecto, cf. I. OPELT, Augustins Epistula 20*. Ein Zeugnis für lebendiges Punisch im 5. Jhd. n. Chr., en Augustinianum 25 (1985) 121-132. En cuanto a la fecha de la ordenación, varían las opiniones de los autores. Según S. Lancel hay que colocarla en el 411/412 (L'affaire d'Antoninus, p. 277); según W. Frend, probablemente en el 415 (Fussala: Augustine's crisis, p. 256). 
tín que, aun sin ser consultada, la población aceptó sin más al candidato propuesto por él ${ }^{28}$.

El nuevo obispo resultó ser todo menos lo que se esperaba de él; resultó falso, perjuro, manipulador, intrigante, timador, depredador de lo ajeno. A san Agustín le dolía particularmente esto último, como se deduce de estas palabras de la carta $20 *$ : "Si otro te lo contase, quizá no creerías que no dudó en comprar quintas a su nombre, no al de la Iglesia; él, un hombre que llegó al episcopado desde el monacato y que no tenía más que lo que llevaba puesto" (Ep. 20*,29). Y de estas otras: "No sólo desea apropiarse de estos bienes, sino hasta de la misma grey de Cristo, a la vez que quiere ser de aquellos de los que dice el Apóstol que buscan sus intereses, no los de Jesucristo (Fil 2,21)"'29. Hinchado con la insolencia del poder, se convirtió en un tirano que amedrentaba a los que declaraban contra él ante el juez, y hallaba su gozo en que se le temiese allí donde veía que no se le amaba ${ }^{30}$. Además -falta particularmente grave para Agustín-, no ejercitaba el ministerio de la palabra y, a la vez que promovía rebeldes a las órdenes sagradas, no dudaba en poner su poder de excomunión al servicio de los propios intereses. Desbordados por las exacciones y el gobierno autoritario de Antonino, los fieles habían elevado una queja contra él a las autoridades eclesiásticas. El personaje resultó persona non grata para buena parte de las comunidades eclesiales confiadas a su cura pastoral, tuvo en danza al episcopado de la provincia con su primado a la cabeza ${ }^{31}$, y hasta recurrió por dos veces a la Sede Apostólica contra sentencias episcopales que le eran adversas. Hasta el emperador llegaron las quejas contra él ${ }^{32}$. Quizá como medio particularmente eficaz para librarse de él, fue acusado de líos de faldas, pero los hechos no pudieron probarse.

"Cuán grande es esta herida de mi corazón véalo quien puede sanarla" ${ }^{33}$, escribe san Agustín a Fabiola, la destinataria de la Carta 20*34. El caso fue particularmente doloroso para él por las consecuencias que se

\footnotetext{
${ }^{28}$ Cf. Ep. 20*,3: "Como lo presenté yo, ellos se fiaron de mí, pues no lo habían pedido espontáneamente, sino que no se atrevieron a rehusar a uno de los míos, que además me agradaba a mí".

${ }^{29} \mathrm{Ep} .20 * 32$.

${ }^{30}$ Cf. Ep. $20^{*}, 4$.

${ }^{31}$ Ahora se trata de Aurelio de Macomades. Sobre él, cf. S. LANCEL, L'affaire, pp. 280-281; A. MANDOUZE, Prosopographie, 127-128.

${ }^{32}$ Cf. Ep. $20^{*}, 29$.

${ }^{33}$ Ep. $20^{*}, 32$.

${ }^{34}$ Sobre esta dama, cf. LANCEL, S., L'affaire de Antoninus, pp. 278-279; también A. MANDOUZE, Prosopographie, pp. 380.
} 
seguían para aquellas comunidades cristianas y para su obispo. Es entonces cuando el santo confiesa al obispo de Roma Celestino su propósito de renunciar al ministerio. Lo hace en estos términos: "He de confesar a tu Beatitud que en este peligro que corren ambas partes -el obispo y la comunidad de Fussala- me atormenta tal temor y tristeza que pienso retirarme del ejercicio del ministerio episcopal" ${ }^{35}$. En su mente estaba sobre todo aquella comunidad cristiana, que le hacía a él en persona responsable del desaguisado y de que, para muchos de sus miembros, resultase odioso el nombre católico ${ }^{36}$. Él mismo nos lo hace saber: "No ya con murmuraciones en voz baja sino a gritos, proclaman que fui yo quien les introduje tan gran calamidad"37. Y en otro pasaje: "Según ellos, tampoco yo merecía el perdón. Respecto a mí, gritaron también cosas que tenía que oír: que había sido el causante de tan gran calamidad por haberles dado una persona que ellos no habían pedido y que les había afligido con tantos males" 38 . El santo veía que, por su culpa, la Iglesia católica corría el riesgo de perder fieles que tanto le había costado llevar a su seno ${ }^{39}$; temía, incluso, que retornasen al paganismo y, en consecuencia, su perdición eterna ${ }^{40}$. Tal fue la causa y las circunstancias que provocaron la tercera crisis agustiniana.

\section{Aspectos de las crisis}

Descritos ya por separado el origen y fondo de cada una de las crisis procede ahora volver sobre ellas considerándolas en conjunto. Una serie de datos saltan a la vista.

a) El primero que cabe señalar es de naturaleza cronológica: las crisis no estuvieron ligadas a una etapa específica de la vida del pastor de

\footnotetext{
${ }^{35}$ Ep. 209,10 .

${ }^{36}$ Cf. Ep. $20 *, 26$.

${ }^{37}$ Ep. $20 *, 15$.

${ }^{38}$ Ep. $20 * 33$.
}

${ }^{39} \mathrm{Cf}$. Ep. $20^{*}, 27$. Al respecto escribe W.Frend: "Antoninus's choice has turned out to be disastrous and the anxious and embarrased letter shows the writer full aware of the damage he had done. The hardwon gains of Catholity unity threatened to be lost, and even worse, Augustine faced a personal crisis" (Augustine's crisis, pp. 254-255).

${ }^{40}$ Cf. Ep. $20,{ }^{* 20}$. Escribe el mismo W. Frend: "The people of Fussala has come to hate him and hate the Catholicism (cf. ep. $20 *, 26$ ). His credibility as a pastor and administrator was in the balance. The pleading tone, as well as the detail which he writes to Fabiola, betrays the depth of his anxiety. With Celestine, he contemplates the final step, that of resignation" (Augustine's crisis, p. 265; cf. también p. 255). 
Hipona, sino que se repartieron todo el arco de su vida pastoral: una al comienzo, otra al medio y otra al final. La posibilidad del conflicto siempre está al acecho; el conflicto mismo no da tregua.

b) El segundo dato diferencia las dos primeras crisis de la tercera. En las dos primeras el santo habla del proyecto o deseo íntimo de refugiarse en la "soledad" que llevaba implícito retirarse del ministerio; sólo en la tercera formula explícitamente el propósito de abandonarlo. Este dato deja entender que detrás de las dos primeras crisis se ocultaba todavía el rechazo inicial a ser ordenado sacerdote, no así en la última. Las dos primeras crisis revelan que el espíritu de san Agustín aún seguía cautivo de su antiguo ideal; las crisis mismas aparecen como una búsqueda inconsciente de razones que justificasen moral y espiritualmente su vuelta a él; en la tercera, en cambio, el antiguo propósito no juega ya ningún papel. Lo dicho significa que las dos primeras crisis implicaban en el fondo, más que un rechazo del ministerio ordenado, una nueva afirmación del viejo ideal; sólo la tercera fue propiamente una crisis sacerdotal. Las otras dos aparecen como coletazos de su primer proyecto de vida, que se resistía a morir.

c) El proyecto en que desemboca la primera crisis queda en el interior de Agustín que sólo lo da a conocer a toro pasado; el deseo vinculado a la segunda crisis lo revela en tiempo real al público que le escuchaba, pero ocultándose tras la pantalla de un siervo de Dios cualquiera; el propósito de la tercera lo hace público también en tiempo real, pero esta vez de forma clara y explícita, en carta personal, a una persona concreta, de más categoría que él, en cuanto obispo de la Sede Apostólica. Lo dicho significa que sólo la tercera revelación le podía comprometer de alguna manera: en principio, en algún momento el Papa podía recordarle su propósito anterior y reclamarle que lo pusiese en práctica; en cambio, el proyecto y el deseo no le comprometía a nada ante los demás. Lo cual está en línea con lo dicho en el párrafo anterior.

d) Cada una de las crisis tiene un fundamento psicológico distinto. La primera la provocó el temor; la segunda, una falta de correspondencia; la tercera, la excesiva confianza. El temor a que su pasado y su presente moral-espiritual le impidiesen desempeñar debidamente el ministerio; la falta de correspondencia de los fieles al esfuerzo que él hacia en pro de ellos; la excesiva confianza que le daba el éxito de la política seguida hasta entonces de promover al episcopado a monjes de su propio monasterio. 
e) Siguiendo en el campo de la psicología, cada una de las crisis está en relación con un aspecto diferente de la persona ${ }^{41}$.

Para una plena salud psíquica el hombre necesita ser para sí mismo, ser con los otros y ser para otros; le es imprescindible poseer el sentido de la identidad propia - ¿quién soy yo?-; el sentido de pertenencia -¿con quién estoy yo?-, así como el sentido de misión -¿para qué estoy yo?-. Teniendo en cuenta estos principios, la primera crisis se puede poner en relación con el sentido de identidad, la segunda con el sentido de pertenencia, la tercera con el sentido de misión. Siguiendo en la misma línea, la primera crisis del pastor Agustín se puede vincular a la falta de la legítima autoestima para desempeñar el ministerio -desubicado ante sí mismo-; la segunda a la falta de la necesaria interacción en el proceso de trasmisión y recepción del mensaje de la fe -desubicado ante los demás-; la tercera como falta de una adecuada adaptación a su ministerio -desubicado en relación a su actividad-. Veamos esto con más detalle.

Toda persona necesita una respuesta clara a la pregunta "¿quién soy yo?". Ahora bien, en el proyecto del joven Agustín de abandonar el ministerio después de considerar su pecado y su miseria, se percibe una percepción errónea, al menos parcialmente, de sí mismo. Su autoimagen descansaba en un autoengaño -su expresión: centrarse en sus dolencias morales-; su autovaloración se trocaba en autodevaluación -su expresión: la conciencia de indignidad personal-, y su autoconfianza se tornaba en inseguridad -su expresión: la sensibilidad a las críticas ajenas-. Pero sólo a sus ojos y de forma provisional. La prueba de que su proyecto de abandonar el ministerio se fundaba en una percepción errónea de sí mismo es el hecho de que, sin que se produjera un cambio en sus objetivas condiciones personales, siguió ejerciéndolo con plena garantía. En realidad, detrás de esa percepción errónea de sí mismo con la consiguiente autodevaluación e inseguridad, cabe advertir un mecanismo de defensa, una forma de represión que recurre a la distorsión del pensamiento, disfrazándolo con otra apariencia. Agustín tenía una idea de sí a la que no quería renunciar: se había identificado en exclusiva con el ideal monástico y en su puesta en práctica fundamentaba su autoestima. Este autoengaño justificaba a sus ojos -y por eso mismo la rebajaba- la ansiedad que le producía el ejercicio del ministerio sacerdotal porque, en su

${ }^{41}$ En este apartado nos inspiramos en G. DE MÉzerville, Ejes de salud mental. Los procesos de autoestima, dar y recibir afecto y adaptación al estrés, ed. Trillas, México 2004. 
opinión, atentaba contra su yo, es decir contra la idea con la que se había identificado ${ }^{42}$. Sólo que, en cuanto mecanismo de defensa, era inadecuado para superar el conflicto planteado entre su ideal personal y la realidad concreta del ministerio que ejercía. Inadecuado porque le impedía tomar conciencia exacta de su realidad y desarrollar los recursos necesarios para enfrentarse al conflicto de manera satisfactoria.

También es básica necesidad humana lograr un cálido sentido de pertenencia mediante el establecimiento de las relaciones adecuadas con las personas significativas en el propio contexto vital. El ministro, que por definición es un servidor, ha de hacerse la pregunta: "¿a quiénes sirvo?", que equivale, en otros términos, a la antes formulada: “¿con quién estoy yo?". En el origen de la que he considerado como segunda crisis de Agustín se percibe una falta de adaptación, la carencia de una adecuada relación interpersonal en el ámbito del ejercicio del ministerio. Entre al menos una parte de sus fieles y él no existía intercambio afectivo; ellos rehusaban seguir las directrices del obispo que tenía conciencia de buscar sólo el bien de ellos. Ajenos a cualquier esfuerzo moral, cual espíritus resignados rehusaban colaborar con su pastor, aceptando a lo más una relación superficial con él en vez de otra más profunda que les exigiese un compromiso mayor. Entre ellos y el pastor faltaba la empatía que les permitiera entrar en sintonía dentro del ámbito específico de su relación; ni el obispo sintonizaba con esos fieles ni esos fieles con él. La deseable identificación con la realidad emocional del otro no pasaba de ser un simple objeto de deseo. Y faltando la empatía, quedaba cerrado el camino hacia la relación madura, la relación personal enraizada en el compartir valores, convicciones e intereses significativos. La relación afectiva requiere correspondencia y es lo que san Agustín no percibía en aquellos fieles. En este momento el problema para el pastor Agustín no estaba en su propio actuar -él no tenía conciencia de haber obrado mal; al contrario, era consciente de haber hecho todo que estaba en sus manos-, sino en no ser aceptado por parte de ellos. Esto en cuanto al origen de la crisis. En cuanto a la solución que él mismo proyectaba, la huida a la soledad, cabe pensar que también aquí estamos ante el mismo mecanismo de defensa de que hablamos en el anterior apartado. Así se puede deducir de la misma reflexión con que él acompaña su planteamiento y que le llevó a superar la crisis, como veremos.

${ }^{42}$ Es cierto que san Agustín nunca dejó de ser monje; que trató de unir la condición episcopal a la monástica; pero también lo es que esa forma de vida monástica no era la que él había elegido para sí. 
Por último, la persona, además de clarificar su identidad personal y su sentido de pertenencia, necesita responder satisfactoriamente a la pregunta “¿para qué estoy yo?”, asociada a la capacidad de generar vida en su acepción más amplia. En el marco de la psicología evolutiva, la pregunta corresponde a la edad madura. La tercera crisis de san Agustín a la que iba unido el propósito de abandonar el ministerio como consecuencia del error en la presentación de un candidato al episcopado, testifica un desajuste con relación a la pregunta formulada. Se trató de una crisis originada por una situación de estrés negativo, fruto de un fracaso sonado en el ejercicio de su ministerio, de un hecho extraordinario y totalmente imprevisto, con consecuencias que él consideraba funestas: la pérdida para la Iglesia católica de numerosos fieles, de la que él se sentía responsable; una pérdida que, si aún no se había hecho efectiva, era muy posible y hasta probable que se produjera; fieles, por otra parte, que, tras el ingente esfuerzo para hacerlos volver a la Católica desde las filas de la rival Iglesia donatista, amenazaban con volver al paganismo. El santo percibía que, en vez de generar vida para la Iglesia a la que servía como pastor, iba a engendrar muerte. Pero, si fue significativo el hecho objetivo causante del mal, no lo fue menos la respuesta personal del santo, cómo lo vivió, lo percibió y lo valoró. El error le alteró emocionalmente produciendo en él reacciones de culpa, de ansiedad, de angustia incluso, de cierta depresión. Su disponibilidad a renunciar al ministerio sacerdotal testimonia su temor de no conseguir superar las consecuencias de su equivocación y de no sobreponerse a la tensión psicológica y espiritual que ello le produciría; pero era sólo un temor, no una certeza. En realidad, esperaba encauzar la situación y redimirse personalmente, siendo la prueba el hecho de no presentar la renuncia de inmediato.

f) Desde el punto de vista moral-espiritual, el abandono del ministerio por parte de san Agustín en el caso de haberse producido no habría sido consecuencia de un abandono previo, afectivo y hasta parcialmente efectivo; no cabría, pues, hablar de una deserción definitiva, después de otras deserciones puntuales. $\mathrm{Y}$ este aspecto distingue las crisis agustinianas de buena parte de las sufridas por los sacerdotes de nuestros días. La lectura de los textos deja claro que a las tres crisis subyace una alta valoración del ministerio sacerdotal. Detrás de la primera crisis se percibe el temor de que su propia indignidad o ineptitud empañe su brillo; detrás de la segunda crisis estaba también la esperanza -manifestada explícitamente por el santo- de hacerlo más fructífero por medio de la oración; detrás de la tercera crisis se hallaba el pesar por haber contribuido al des- 
prestigio del mismo en la persona del obispo Antonino. A esto no obsta la posibilidad contemplada de que tanto la primera como la segunda crisis no fueran sino un mecanismo de defensa; más bien lo confirma. En efecto, tal mecanismo sólo podía resultar eficaz desde la consideración de la alta dignidad y exigencia del ministerio sacerdotal.

\section{La superación de las crisis}

San Agustín acabó sus días siendo obispo de Hipona. Eso significa que superó sus crisis y no hizo realidad su proyecto, deseo y propósito de abandonar el ministerio. Pero ¿en qué se apoyó para superarlas? Los textos que nos hablan de ellas nos informan también de este aspecto. Veamos, de nuevo, cada una por separado.

\section{a) Primera crisis (Conf. 10,43,70)}

$\mathrm{El}$ proyecto de retirarse a la soledad, con el consiguiente abandono del ministerio, no pasó de un simple proyecto. Llama la atención que lo que le llevó a superarla no guarda relación directa con lo que la provocó. Aunque el santo la presenta como crisis con base moral, su resolución tuvo lugar en el plano espiritual: "Mas tú me lo prohibiste y me diste fuerza, al decirme: Por eso murió Cristo por todos, para que los que viven ya no vivan para sí, sino para aquel que murió por ellos (2 Cor 5,15)"“4.

Este texto contiene las tres referencias fundamentales que, de modo unitario, influyeron en que el santo abandonase el proyecto de huir a la soledad: Dios Padre ("Tú me lo prohibiste"), la Escritura ("diciendo"), Jesucristo ("por eso murió Cristo..."). El ministro inseguro leyó la Escritura como palabra de Dios que le comprometía personalmente. El texto paulino, tomado de la segunda carta a los Corintios, le puso ante sus ojos la muerte de Cristo y lo que esa muerte implica para el cristiano. Cristo -escribe san Pablo- murió por todos; no por el círculo de amigos o por sus seguidores sólo, sino por todos. Afirmado el hecho, de él deduce el Apóstol que cuantos viven, habiendo recibido la vida precisamente de la muerte de Cristo, ya no pueden vivir para sí, sino para quien murió por ellos. Y vivir para quien murió por ellos implica entregar la vida por aquellos por los que murió él, es decir, por los demás. El presbítero de Hipona captó bien el mensaje: él, que no hacía mucho había recibido de

${ }^{43}$ Conf. $10,43,70$. 
Cristo la vida, no podía dedicarla sólo al reducido círculo de sus amigos; debía aceptar el servicio a la entera comunidad cristiana. El santo interpretó ese texto apostólico como un veto divino a que siguiese adelante con su proyecto de regresar al monasterio, abandonando el ministerio: "Tú me lo prohibiste al decirme...". A Dios no le faltan títulos, que san Agustín reconocía, que le otorgan ese derecho de veto. Es más que probable que el santo pensase entonces en su propia condición de "siervo de Dios". Basta recordar la reflexión que, en su momento, le llevó a aceptar la ordenación presbiteral, a pesar de que frustraba sus planes de futuro: "El siervo no debe llevar la contraria a su amo". Es derecho del amo modificar los planes del siervo, pero al siervo no le está permitido oponerse a la voluntad del amo. Cuando el siervo tiene conciencia de serlo y de lo que conlleva, como era el caso de Agustín, siervo por libérrima voluntad, no le queda sino aceptar el veto. No aceptarlo equivaldría a una fuga inútil. Su libertad habría sido más ficticia que real, como la de todo fugitivo ${ }^{44}$.

La referencia cristológica que Dios le puso ante los ojos mediante el texto de la Escritura eliminaba de cuajo el verdadero obstáculo de Agustín para seguir en el ministerio: su deseo de vivir en "soledad". Eliminado ese obstáculo, el problema moral, que presentamos antes como tapadera de otro, dejó de ser impedimento. En el texto paulino encontró no sólo el veto de huir a la "soledad", sino también la motivación para continuar en el ministerio. De hecho, la cita del mismo va precedida de la interpretación agustiniana: "Tú me lo prohibiste y me diste fuerza". La entrega de Cristo a la muerte por todos significaba para él lo uno y lo otro. Un texto suyo puede resultar iluminador al respecto. Dice en un sermón: "Si uno, considerando su debilidad, siente que desfallece ante lo que el Señor le ordena, se siente confortado con su ejemplo y, si aun imitar su ejemplo es superior a las propias fuerzas, cuenta con el que le dio el ejemplo para que le otorgue también la ayuda"45. Parece que el predicador estaba describiendo aquí su caso particular.

San Agustín encontró en Jesucristo un programa de actuación y el impulso para ejecutarlo. Su propia debilidad moral no debía ser impedimento para seguir en el ministerio. Un planteamiento que mantendrá años más tarde, en el marco de la exposición del lavatorio de los pies de Jesús a sus discípulos. Sirviéndose, entre otros textos bíblicos, de Cant 5,2-3 y de Mt 24,12, el predicador transforma el relato evangélico en una

\footnotetext{
${ }^{44}$ Cf. Conf. 3,3,5.
}

${ }^{45}$ En. Ps. 56,1. 
viva exhortación a los monjes a aceptar el ministerio apostólico para abrir las puertas a Cristo que pasa frío. La objeción de aquellos de que, teniendo los pies lavados, no pueden volver a mancharlos, no le echa atrás en su propuesta; al contrario, encuentra en el hecho de que Cristo lava los pies el argumento para rebatírsela. El santo parte de que el ejercicio del ministerio acarrea consigo casi inevitablemente manchas morales: "Pero he aquí que me levanto y abro. ¡Cristo, lávalos (los pies); porque no se ha extinguido nuestra caridad, perdónanos nuestras deudas como también nosotros perdonamos a nuestros deudores (Mt 6,12). Cuando te escuchamos, en los cielos exultan contigo los huesos humillados; pero, cuando te predicamos, pisamos la tierra a fin de abrirte las puertas y, por eso, si se nos critica, nos perturbamos; si se nos alaba, nos inflamos. Lava nuestros pies antes limpiados, pero manchados cuando, a fin de abrirte las puertas, caminamos por la tierra"46.

b) Segunda crisis (Coment. al salmo 54,8-9)

El pastor Agustín tampoco dio curso al deseo de retirarse, aunque fuera provisionalmente, a la "soledad", abandonado el ejercicio del ministerio. Pero un deseo así no puede quedar insatisfecho sin más, pues corre el peligro de acabar en sentimiento de frustración. Si el santo no lo secundó fue por sólidas razones que expone en el mismo texto en que revela ese deseo. Aunque habla de un siervo de Dios cualquiera, es fácil percibir -repetimos- el tono de una confesión personal.

Dos son los argumentos que sostuvieron la fidelidad del santo al ministerio: la conciencia del deber y una buena dosis de realismo, apoyados respectivamente en el ejemplo de san Pablo y en la reflexión desde la experiencia de la vida.

El santo se miró en el espejo de san Pablo que, a pesar de desear morir y estar con Cristo, más ventajoso para él, consideró necesario permanecer en esta vida por el bien de los demás (cf. Fil 1,23-24) ${ }^{47}$. Refiriéndose al Apóstol y sirviéndose de la imagen de la paloma, dice el predicador: "La paloma, al estar atada por el afecto y no por un interés personal, no podía volar, no porque no lo mereciese aún, sino por las exigencias de su oficio". El texto sugiere dos reflexiones. La primera guarda relación con la imagen usada. Sabido es que, sobre todo en la controversia con los

\footnotetext{
${ }^{46}$ Io. eu. tr. $57,6$.

${ }^{47}$ Cf. En. Ps. 54,8 .
} 
donatistas, la paloma se convierte en la boca y pluma de san Agustín en símbolo de la Iglesia en cuanto compuesta de fieles animados por la caridad en la unidad ${ }^{48}$. Ahora bien, si la Iglesia es madre y no puede dejar a sus hijos sin la atención que necesitan, el ministro que la representa no puede abandonar el ministerio si no está garantizada esa atención ${ }^{49}$. El ministro que contempla esa posibilidad, debe pensar siempre con criterios eclesiales y no con criterios puramente personales. La segunda reflexión se refiere a la fuerza que impulsa el ministerio. Lo que verdaderamente lo sostiene es el afecto, el amor a los que se ha de servir. Cuando ese amor existe, cualquier razón en contra que se presente se sentirá como una excusa; por el contrario, cuando falta ese amor, cualquier excusa se verá como una razón. La conciencia del deber es importante, pero puede no bastar si falta una fuerza que impulse su cumplimiento. En el caso presente, el amor a los demás tiene esa virtualidad.

Un segundo argumento lo extrajo el pastor de Hipona de la vida misma. Él tenía ya una larga experiencia de vida pastoral y sabía bien que la debilidad humana no es planta que germine sólo en una determinada estación del año, en un específico lugar o en unas condiciones muy concretas, sino que pulula siempre y por doquier; que no hay tiempo, espacio o situación en que no eche raíces. Esa experiencia le decía que a dondequiera que vaya uno se encontrará con personas indeseables. El santo no hablaba de teorías, sino de hechos. Deseando tener alas para volar al desierto, pensaba en lo que allí sucede: “¿Por qué razones pensáis, hermanos, que los desiertos están llenos de siervos de Dios? Si les hubiera ido bien en compañía de los hombres, ¿se habrían apartado de ellos? Y, sin embargo, ¿qué es lo que hacen ellos también? Ved que se alejan, que huyen, que se quedan en el desierto, pero ¿acaso permanecen solos? La caridad los sujeta para que permanezcan en compañía de muchos otros. Pero entre esos muchos no faltan quienes los ponen a prueba" 50 . Y aduce la razón: "Pues es inevitable que en todo grupo humano haya personas indeseables" "S1. San Agustín se ha despertado del sueño y se ha devuelto a la realidad.

${ }^{48}$ Cf. Io. eu. tr. 6,12-17; Bapt. 3,17,22-18,23, etc. Cf. M.-F. BERROUARD, La colombe, en Oeuvres de saint Augustin, BA 71 (1993) 877; P. BORGOMEO, L'Eglise de ce temps dans la prédication de saint Augustin, Paris 1972: 279-356.

${ }^{49}$ En la $e p .228$, escrita ya al final de su vida a petición del colega en el episcopado Honorato que le pedía consejo sobre cómo actuar en aquellos momentos dramáticos de la invasión de los vándalos arrianos, deja clara constancia de ello.

${ }^{50}$ En. Ps 54,9.

${ }^{51} \mathrm{Ib}$. 
Una vez anclado en el realismo, prosigue su reflexión tratando de responder a la pregunta de por qué sucede así. La respuesta se la facilita su interpretación providencialista de la historia: "Dios mismo, que sabe que necesitamos ser sometidos a prueba, pone a nuestro lado también a algunos que no han de perseverar; más aún, a algunos tan hábiles en la simulación que ni siquiera han dado el primer paso en aquella vida en la que deberían haber perseverado. Él sabe que nos es necesario soportar a los malos, para así progresar en el camino del bien" ${ }^{2}$. El ministro no debe interpretar demasiado a la ligera la presencia de malos, incluso en su comunidad cristiana, como un fracaso personal en el ejercicio de su ministerio, pues esa realidad no está fuera de los planes de Dios. En el trasfondo de esta afirmación está la teología agustiniana de la Ecclesia permixta, de una Iglesia en que temporalmente conviven justos con pecadores, que con tanto ahínco defendió contra la tesis de donatista de una Iglesia totalmente pura ya en el tiempo presente ${ }^{53}$. Y precisamente porque cuadra con los planes de Dios, redundará en bien personal del ministro. En todo caso, su ministerio no puede desentenderse de ellos: "Amemos a nuestros enemigos; corrijámoslos, castiguémoslos, excomulguémoslos, separémoslos incluso de nosotros, pero con amor (cf. 2 Tes 3,14-15)" ${ }^{\prime \prime 54}$.

$\mathrm{El}$ argumento de experiencia lo resume el predicador en estos términos: "A dondequiera que vayas se te juntarán otros, irán contigo allí, simularán querer vivir contigo y no podrás rechazar la compañía del hermano. También allí se mezclarán contigo los malos; pues aún allí tienes que ejercitarte en la prueba" 55 . Y como prueba concluyente de la afirmación de que ningún grupo humano, por selecto que sea, está exento de malos, aduce el ejemplo del colegio apostólico a cuyo frente estaba "nuestro Consolador, Señor, Rey, Emperador y Creador, creado entre los hombres". También en el grupo de los Doce se coló uno a quien el Señor tuvo que soportar. Importante en este caso es el primer apelativo, el de Consolador, dado a Jesucristo: el ministro que sufre la presión de los malos hallará consuelo en él, que la sufrió antes ${ }^{56}$.

El realismo a que acude el santo no se limita a constatar que vaya donde vaya, incluido el monasterio, a donde deseaba retirarse, encontrará malos ${ }^{57}$. El santo contempla todavía otra posibilidad: huir, es decir,

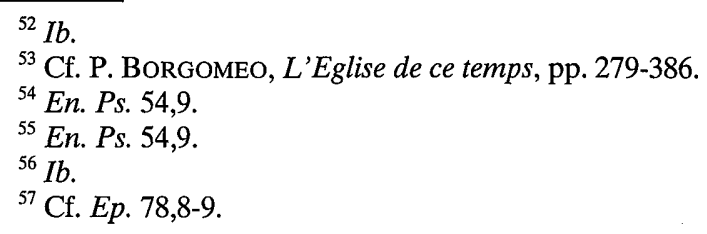


refugiarse en la propia conciencia, en la propia interioridad, donde encontraría cierta soledad en la que descansar. Pero también esta posibilidad queda excluida por una mirada realista. Tampoco allí hallará la paz, aunque ahora será el amor el que le turbe. Estará sólo en su conciencia, pero no en la caridad; interiormente le puede consolar la conciencia, pero fuera no le faltarán tribulaciones que le quiten la paz. Entonces, se pregunta, ¿qué hacer cuando, en el plano personal el ministro está tranquilo, pero la preocupación por los demás turba su paz? El salmo que viene comentando le responde: "Esperaba a quien me salvase del miedo y de la tempestad" (Sal 54,9). Pero ¿quién es ese? La respuesta se la da ahora el evangelio: "No te queda sino gritar: '(Sálvame), Señor, que perezco' (Mt 14,30). Que te tienda su mano aquel que camina intrépido sobre las olas; que te saque a flote cuando el miedo te hunda, que sustente en él tu seguridad; que te hable en tu interior y te diga: 'Mira lo que yo sufrí'. Tal vez soportas a un hermano malvado o un enemigo exterior; ¿a cuántos no soporté yo?" 58 . Los apóstoles dejaron a los ministros que les habían de suceder en la Iglesia el camino que debían seguir en las dificultades que puedan experimentar en el mar de este mundo: no dejar que duerma su fe y gritar a Cristo para que acuda en su auxilio.

\section{c) Tercera crisis (Carta 209,11)}

El obispo Agustín tampoco llevó a cabo su propósito de renunciar al ministerio con ocasión del error cometido al promocionar como obispo de Fussala al joven monje Antonino. Consta que siguió ejerciendo de obispo hasta el fin de sus días. Por la información que poseemos, no debe resultar extraño ni hay que pensar en un cambio de parecer. El propósito de renunciar estaba vinculado a una condición: "Si veo que aquel al que apoyé para que fuese obispo por mi imprudencia devasta la Iglesia de Dios y, lo que Dios no permita, perece esa Iglesia junto con su devastador" 59 .

No sabemos a ciencia cierta cómo acabó el asunto de Antonino. Nuestra información directa acaba en el momento procesal en que el obispo rebelde, disconforme con las decisiones de un concilio provincial, apeló por segunda vez a la Sede Apostólica, circunstancia que provocó que san Agustín escribiera la carta 209 al papa Celestino I y la $20^{*}$ a la noble dama Fabiola, que le ofrecía hospitalidad en Roma. Pero el hecho

\footnotetext{
${ }^{58}$ Cf. En. Ps. 54,10 .

${ }^{59}$ Ep. 209,11.
} 
de que Agustín no hiciese efectiva su renuncia al ministerio episcopal deja entender que no sucedió lo que él temía o, lo que es lo mismo, que el obispo Antonino no encontró apoyo en el Papa y acabó sometiéndose, y que las iglesias tan vejadas por él se mantuvieron en la comunión católica $^{60}$. Una carta de Agustín a Quodvultdeo, diácono de Cartago y sucesor de Aurelio en la cátedra episcopal de la capital norteafricana, en la que recomienda y solicita que ayude en sus gestiones al presbítero de Fussala, portador de su carta, deja entender que dicha comunidad volvió a quedar bajo la cura pastoral del obispo de Hipona. De hecho, la carta concluye en estos términos: "No podemos abandonar a estos hombres, que no sólo son nuestros colonos, sino, lo que es más, nuestros hermanos y que en la caridad de Cristo están bajo nuestro cuidado"61.

En primer lugar, al proyectar abandonar el ministerio, el santo aceptó su culpa sin buscar excusas. Fiel a las palabras del Apóstol (cf. 2 Tim $4,1)$ quiso juzgarse a sí mismo para evitar ser juzgado por el Señor. Pero al mismo tiempo, en vez de dedicarse únicamente a lamentar su error, puso todo su empeño en reparar el mal causado. En ese sentido hay que entender los distintos procesos judiciales abiertos contra Antonino, su actuación tratando de evitar tanto la excesiva dureza como el dejar impunes sus actos delictivos, la benevolencia mostrada hacia él que llegó hasta conservarle la dignidad episcopal, aunque disminuyendo su ámbito de potestad $^{62}$ y excomulgándole hasta que no indemnizara a los que había perjudicado ${ }^{63}$; el compromiso alcanzado con él para que siguiese siendo obispo de otras comunidades de su antigua diócesis que no le rechazaban ${ }^{64}$; su disponibilidad a aumentárselas en determinado momento, siempre bajo ciertas condiciones ${ }^{65}$; su intervención ante el Primado para atender

${ }^{60} \mathrm{Ch}$. Munier imagina cuál pudo haber sido el final de la historia: "l'intervention de Fabiola aura été determinante. Antoninus se sera laissé convaincre de retirer sa plainte; il aura compris en fin l'indécence de son obstination, le scandale suscité par cette procédure interminable, les intérêts supérieures de la pax de l'Église catholique; il aura accepté -pour le reste de ses jours- à ne plus rechercher 'que les choses d'en haut et non plus les coses terrestres' (Col 3,1), comme l'y exhortait Agustin. Et il me plaît assez d'imaginer que 'la très religieuse, la très venerable, la très genereuse' dame Fabiola lui vint en aide pour réaliser ce sage propos" (La question des appels à Rome, p. 298).

${ }^{61}$ Ep. 224,3. Cf. LANCEL, S., L'affaire d'Antoninus, p. 285.

${ }^{62}$ Cf. Ep. $209,5$.

${ }^{63}$ Cf. Ep. 209,6.

${ }^{64}$ Cf. Ep. 20*,9. En la carta 20* "Nous recueillons les confidences d'Augustin, blessé aux tréfonds de son être et plaidant malgré tout l'indulgence pour son fils Antoninus, s'il accepte d'oeuvrer pour la paix de l'Église" (CH. MUNIER, La question des appels à Rome, pp. 293-294.

${ }^{65}$ Cf. Ep. $20 *, 13.18$. 
necesidades de los fieles de la localidad de Togonoeto ${ }^{66}$; el perdón que obtuvo del Primado para los habitantes de esta población ${ }^{67}$; el no transigir con otras exigencias del obispo culpable; el haber antepuesto la verdad a la propia conveniencia, sacando a relucir las mentiras o silencios del encausado ${ }^{68}$; el haberse mantenido en segundo plano cuando pareció oportuno, el no presentarse donde no era bien visto al juzgar que su presencia podía ser interpretada como una provocación ${ }^{69}$; el acudir a la llamada del Primado cuando solicitaba su presencia ${ }^{70}$; el haber pedido el apoyo del Papa brindándole otra visión de los hechos, distinta de la que pudiera ofrecerle Antonino; el haber escrito a Fabiola para que influyese sobre él, etc. ${ }^{71}$.

\section{Aspectos de la superación de las crisis}

Visto cómo san Agustín logró superar cada una de sus crisis, procede hacer ahora unas reflexiones de carácter global sobre esa superación, centrándonos en los aspectos humano, cristiano y psicológico.

a) La superación de las crisis fue posible gracias a la madurez humana del santo. Esa madurez humana queda reflejada en datos aportados en el contexto de la segunda y tercera crisis. En la segunda, en su apelar al realismo. Antes que volar hacia un paraíso que la experiencia le mostraba como inexistente, optó por seguir anclado en su realidad. Vivir de sueños es propio de un adolescente, no de un hombre maduro. Es el mismo pastor de Hipona el que, en un contexto de reclutamiento de candidatos para el ministerio sacerdotal y para la vida religiosa, critica y consecuentemente rechaza todo intento de idealizar uno y otro tipos de vida. La razón es obvia: lo normal es que toda presentación idílica e irreal acabe en decepción y la decepción en defección ${ }^{72}$. En la tercera crisis, en el aceptar su personal responsabilidad, reconociendo que, ante la situación inesperada, debía haber actuado diversamente: “¿Qué debí hacer entonces, en buen criterio, sino diferir asunto tan grave?" ${ }^{3}$. Luego, en el

\footnotetext{
${ }^{66}$ Cf. Ep. $20 *, 10$.

${ }^{67}$ Cf. Ep. $20 *, 20$.

${ }^{68}$ Cf. Ep. $20 *, 11$.

${ }^{69}$ Cf. Ep. $20 *, 15$.

${ }^{70}$ Cf. Ep. $20 *, 12$.

${ }^{71}$ No obstante, W. Frend juzga que "Fussala may take its place as a milestone along the road that led to the collapse of Roman and Catholic North Africa as well as to the decline of their great protagonist, Augustine of Hippo" (Augustine's crisis, p. 265).

${ }^{72}$ Cf. En. Ps. $99,12-13$.

${ }^{73}$ Cf. Ep. $20 *, 3$.
} 
no tomar su error como excusa para abandonar el compromiso de servicio a la Iglesia contraído con su ordenación, como oportunidad para realizar su viejo sueño de retirarse al monasterio. Por último, en el llorar su error, pero sin quedarse sólo en lamentos, interviniendo de forma activa, pero discreta, cuando así lo exigían las circunstancias, en la solución del problema que él había creado.

b) La superación de las crisis fue posible también gracias a su sólida base cristiana. Esta solidez la revela la fuente donde buscó luz -la sagrada Escritura-, los modelos que siguió -Jesucristo y san Pablo-, y su conciencia eclesial.

Tanto en la primera como en la segunda crisis, el recurso a la Sagrada Escritura se mostró eficaz y decisivo. Según su relato, en la primera encontró luz y fortaleza en el texto de 2 Cor 2,15: "Tú me lo prohibiste y me diste fuerzas". En la segunda, el texto de Fil 1,23-24 le aportó el ejemplo, a la vez iluminador y estimulante, de san Pablo. Detrás de la superación de sus crisis hay una lectura personalizada de la Escritura. Antes que como fuente para la instrucción de los demás la entendía como fuente de iluminación personal.

Los modelos en que el pastor de Hipona se fijó fueron, en la primera crisis, Jesucristo y, en la segunda, ante todo san Pablo, pero también Jesucristo. Pero estos dos modelos no actuaron de la misma manera. El ejemplo de san Pablo se adecuaba específicamente a su crisis; el apóstol y el obispo, con sus diferencias, se encontraban básicamente ante el mismo dilema: optar por seguir sirviendo a los demás en detrimento de la propia paz y tranquilidad. Distinta era, en cambio, la relación entre el santo y Jesucristo en la primera crisis: es obvio que Jesucristo no tuvo que solucionar un problema moral-espiritual como el de Agustín, para que le sirviera de ejemplo. Si, de hecho, Jesucristo le sirvió de ejemplo fue en otro nivel más profundo: el de la entrega de la propia vida por los demás hasta las últimas consecuencias. Ante una opción tan radical, las deficiencias morales que Agustín esgrimía tenían más bien la apariencia de simples excusas. En la segunda crisis, en cambio, sí se da cierto paralelismo entre la situación de Jesucristo y la de san Agustín. Ante la existencia de malos en la comunidad cristiana que están en el origen de la crisis agustiniana, el santo vuelve los ojos a Él que también tuvo que soportar, en su reducido grupo de apóstoles, a Judas. En realidad, aquí el obispo de Hipona no contempla a Jesucristo como ejemplo que imitar, sino como consuelo en que descansar. El haber soportado en su compañía a quien le iba a trai- 
cionar lo convierte en lenitivo para los ministros de su Iglesia que sufren la opresión de los malos.

Ninguna de las crisis las resolvió san Agustín desde un interés estrictamente personal, sino eclesial. Esta idea la expresa el santo, con relación a su segunda crisis, sirviéndose de una imagen de la paloma que le ofrece el salmo 54 que está comentando. De ella dice: "La paloma, al estar atada por el afecto y no por un interés personal, no podía volar, no porque fuese pequeño su mérito, sino por las exigencias de su oficio". La paloma a que se refiere aquí es san Pablo que había acumulado ya suficientes méritos para optar al descanso, pero el santo lo trae a colación porque en la de él ve reflejada en parte su propia situación. Si se hubiese dejado llevar únicamente del interés personal y no del amor a los fieles confiados a su ministerio, lo probable es que hubiese "volado", es decir, abandonado el ministerio. $\mathrm{Y}$, siempre en el contexto de la segunda crisis, habla de la renuncia a buscar la paz y tranquilidad, porque sabía que el amor a los fieles iba a turbársela. Si el santo logró superar la primera crisis no fue porque viera en ella la posible solución a sus problemas morales, sino porque comprendió que, como Cristo, tenía que vivir para los demás, sin que para ello fuesen óbice sus propias debilidades. Igualmente, superó su tercera crisis -así es razonable suponer-cuando pudo comprobar que los fieles víctimas de su decisión precipitada al elegirles obispo habían decidido permanecer fieles a la Iglesia Católica. Si hubiese puesto delante sus propios intereses, no los de Jesucristo en la persona de sus fieles, las diferentes crisis se hubiesen resuelto quizá diversamente.

c) Desde la perspectiva psicológica cabe interpretar la superación de las crisis desde las mismas claves utilizadas para la interpretación de las crisis.

A nivel psicológico, el presupuesto para la superación de la primera crisis pasó por una nueva autoimagen, consistente en comprenderse desde su condición de cristiano: el texto paulino le hizo tomar conciencia de contarse entre "los que viven" con vida divina. Esa nueva autoimagen implicaba una nueva autovaloración: el criterio de valor ya no era moral, sino religioso; a sus ojos pasó a contar menos cómo era y más lo que era. $\mathrm{Su}$ atención se desplazó del aspecto negativo de la propia indignidad moral al positivo que representaba la llamada de Dios, que le llegaba por medio del texto paulino, a vivir para Cristo: "ya no vivan para sí, sino para Aquel que murió por ellos". Y esta nueva autovaloración se transformó en autoconfianza con fundamento nuevo: ya no radicaba en sus propias facultades, en su integridad moral, sino en la fuerza de Dios que 
le llamaba: "Tú me diste fuerzas". Las nuevas actitudes que habían arraigado en su corazón le llevaron a autoafirmarse en el ministerio: con plena libertad y consciencia optó por seguir en él, aparcando el proyecto de huir a la soledad. Desapareció su dependencia de los juicios negativos ajenos, que le encaminaban por la senda de la autoanulación; la llamada de Dios por medio de san Pablo equilibró y superó el peso de la crítica de sus adversarios o enemigos. Comenzó a ver el ministerio como el espacio más adecuado para su autorrealización, incluso como siervo de Dios, como el campo en que podía desarrollar todas sus potencialidades como tal. Al inicial autodesprecio que había suscitado su proyecto de fuga sucedía una fundada autoestima: la del que se siente llamado por su Señor a continuar su propia obra. Lo cierto es que san Agustín, dejando de lado sus complejos anteriores, pasa a proclamar: "en ti, Señor, deposito mis preocupaciones" $"$.

La segunda crisis la relacionamos antes con el sentido de pertenencia que responde a la pregunta “¿con quién estoy yo?”. La crisis tenía su origen en la dificultad de intercambio afectivo y en la falta de empatía que dificultaba la interrelación madura fundada en el compartir valores e intereses. Pero ese compartir es cosa de dos partes y basta que una no quiera para que resulte inviable. Ni el obispo podía cambiar el modo de actuar que le reclamaba su conciencia, ni estaba en sus manos modificar la actitud de determinados fieles. Ese camino, en cuanto implicaba compartir valores e intereses, lo encontraba cerrado; la superación de la crisis, pues, no pasaba por ahí, sino por trascender ese tipo de relación y situarse en otra forma más evolucionada de afecto en la vida humana, conocida como amor de "ágape". Este "ágape" no depende de afinidades de carácter, de intereses y valores, pues trasciende la dimensión interpersonal que caracteriza a las demás formas de afecto. Se trata de un amor unilateral y universal, que supera la necesidad de dar y recibir afecto y que, por eso mismo, demanda una mayor madurez y profundidad de tipo espiritual. Sustituye la lógica del dar y recibir por la del solo dar y en este sólo dar encuentra la más plena satisfacción. Esto explica que "las personas animadas por este tipo de amor son probablemente las más felices y las menos expuestas a las neurosis, porque su preocupación, aunque emana del yo, no se enfoca a la propia satisfacción ni está confinada a ésta en el ámbito del intercambio afectivo"75. Ahora bien, cuando san

${ }^{74}$ Conf. $10,43,70$

${ }^{75}$ G. M. KINGET, On being human: A systematic view, New York 1975, p. 109, citado por G. DE MÉzERVILLE, Ejes de salud mental, p. 166. 
Agustín, refiriéndose a san Pablo, pero pensando también en sí mismo, dice: "La paloma, al estar atada por el afecto y no por un interés personal, no podía volar... por las exigencias de su oficio", está describiendo ese amor de "ágape". Es el fundamento de la superación de la crisis: el amor que se da sin esperar contrapartida. La superación del amor que espera reciprocidad hacía innecesaria la deseada huida a la soledad del monasterio en la que podía disfrutar del dar y recibir afecto, de la amistad de los amigos.

La tercera crisis fue -dijimos- la más aguda y la más concreta de todas. Tratándose de un hecho puntual, con consecuencias que él con razón preveía funestas, no bastaba una solución de futuro -evitar reincidir en el error-, pues urgía una solución de presente. El santo se mostró capaz de enfrentarse a la enorme tensión interior que le produjo y acertó a manejarla. Puso en acción sus propios recursos y obtuvo un resultado positivo; prueba de ello es que no se vio abocado a hacer realidad su propósito de renuncia al ministerio. Fue capaz de encarar el problema porque su tensión tenía una base objetiva, no subjetiva: el hecho que la desencadenó había sido real, real el problema y él lo supo captar en sus justos términos. Su reacción personal también había sido proporcionada a lo que él veía que estaba en juego. En él no se dieron distorsiones cognitivas, al menos que afectasen al núcleo de la cuestión, ni, para superar la tensión, necesitó modificar su apreciación del hecho y de las consecuencias. Por otra parte, su forma coherente de ver la realidad y a sí mismo dentro de ella, marcada por la fe cristiana y la comunión eclesial, contribuyeron a su éxito en el manejo de la situación. Ante todo, no dejó que la atenazaran ni el sentimiento de culpa, ni la ansiedad, ni el temor o el miedo; no se trataba de camuflar la realidad, sino de no dejarse abatir por ella; no se encerró en sí mismo, dándose por vencido; antes que sucumbir prefirió enfrentarse al problema, primer paso hacia su solución. Percibiendo el problema en su dimensión real, rechazó la huida; prefirió el combate porque ninguna sensación de impotencia se lo impedía; renunció a resignarse porque nada veía que fuera absurdo y sin sentido. Es cierto que le dejó la puerta abierta -la renuncia al ministerio-, aunque sólo para la eventualidad de una derrota en el combate. Se movió para cambiar lo susceptible de ser cambiado. Su confrontación fue directa, aunque, en un segundo momento, llegó a un compromiso, limitado, con el causante de la situación, no aceptando todo cuanto él solicitaba, lo que habría significado una claudicación que dejaría irresuelto el problema objetivo y el subjetivo. 


\section{Conclusiones}

Del repaso a las tres crisis agustinianas, es posible extraer algunas conclusiones generales sobre las crisis sacerdotales. En primer lugar, san Agustín es testigo de una verdad afirmada por la experiencia: no hay una edad específica para las crisis; pueden llegar en cualquier etapa de la propia vida: en la juventud, en la madurez, en la vejez. En segundo lugar, no todas las crisis sacerdotales tienen la misma raíz antropológica: unas surgen directamente de la persona, otras de su relación con los demás y otras de la relación con la propia actividad. La crisis espera tanto al que no ha resuelto el problema de la identidad personal, como al que se ve envuelto en problemas con relación al grupo, o al que no ha encontrado la justa relación con la tarea que tiene asignada. En tercer lugar, no todas las crisis tienen el mismo sustrato psicológico: está expuesto a la crisis quien vive en el temor morboso a la propia infidelidad, o el que no logra sintonizar con los beneficiarios de su ministerio, o el que, desde la excesiva confianza en su valía o experiencia, toma decisiones arriesgadas. En cuarto lugar, por lo que se refiere al plano moral-espiritual, si hay crisis sacerdotales que inequívocamente son fruto de una previa dejación, más o menos inconsciente, del ministerio sacerdotal, las hay también que provienen de una afirmación consciente del mismo; unas crisis las provoca una infidelidad de hecho al ministerio, otras las provoca una afirmada voluntad de fidelidad al mismo. En quinto lugar, lo visto en san Agustín muestra que, a veces, las crisis ocultan problemas que no pudieron ser plenamente resueltos en su momento; que no siempre es fácil mantener simultáneamente dos fidelidades a primera vista contrapuestas, por legítimas que sean, y que el saber integrarlas reclama tiempo. Es el conflicto entre dos opciones libres que tienen distinto fundamento. Aun entre opciones libres hay preferencias y, hasta de forma inconsciente, la preferida trata de desplazar a la otra: en el caso de Agustín, su opción por la vida retirada, arraigada en su psicología, y su opción por el ministerio, que brotaba de su fe. En sexto lugar, que la crisis puede provenir de los resultados o, mejor, de la falta de resultados, después de haber hecho todo lo que estaba en las propias manos.

El caso de san Agustín muestra también que las crisis pueden tener una solución positiva cuando el sacerdote que las sufre tiene la adecuada base humana y cristiana.

Por último, las crisis suponen un peligro, pero también y sobre todo una oportunidad. El peligro de la pérdida de seguridad y hasta del abandono del ministerio; la oportunidad de poner cimientos más sólidos al 
edificio del ministerio. Las crisis maduraron al Agustín pastor llevándole a fundamentar mejor, espiritual y teológicamente, su servicio pastoral. $\mathrm{Si}$ el santo fue un gran pastor se debe en buena medida a esas crisis que le obligaron a estar motivándose continuamente para seguir en la brecha. Él supo manejar las crisis y convertirlas en fuerza motivadora de la propia existencia. En efecto, si un problema no resulta de una situación imposible, sino de una solución inadecuada ${ }^{76}$, él supo encontrar la solución correcta que suprimió el problema. El caso de san Agustín nos viene a decir que no hay que temer el término crisis. En realidad, las crisis humanas son sólo ocasiones en que hay que tomar decisiones adecuadas sean del signo que sean.

${ }^{76}$ Cf. M. MCKAY ET AL., Técnicas cognitivas para el tratamiento del estrés, Barcelona 1985, pp. 71-72, citado por G. DE MÉZERVILLE, Ejes de salud mental, p. 282. 